\title{
Dentigerous Cyst with Ectopic Third Molar Tooth in Maxillary Sinus causing Chronic Rhinosinusitis
}

Nitin Kumar Jain, Siddharth Vashistha, Megha Jain

\begin{abstract}
Ectopic eruption of teeth into a region other than the oral cavity is rare although there have been reports of teeth in the nasal septum, mandibular condyle, coronoid process, palate, chin and maxillary sinus. Eruption of ectopic teeth in maxillary sinus usually is found incidentally on routine radiological investigations. We present a case of an ectopic maxillary third molar tooth with dentigerous cyst that caused chronic purulent sinusitis in left maxillary sinus.
\end{abstract}

Keywords: Ectopic teeth, Sinusitis, Third molar, Dentigerous cyst.

How to cite this article: Jain NK, Vashistha S, Jain M. Dentigerous Cyst with Ectopic Third Molar Tooth in Maxillary Sinus causing Chronic Rhinosinusitis. Clin Rhinol An Int J 2013;6(2):106-107.

\section{Source of support: Nil}

Conflict of interest: None declared

\section{INTRODUCTION}

Tooth development results from a complicated multistep interaction between the oral epithelium and the underlying mesenchymal tissue. A series of complex tissue interactions result in the formation of mature teeth. Abnormal tissue interactions during tooth development may potentially result in ectopic tooth development and eruption. ${ }^{1}$

The ectopic development of teeth in nondental localizations have been reported in the nasal cavity, chin, maxillary sinus, mandibular bone, palate and orbital cavity. ${ }^{2-4}$ Ectopic teeth may be permanent, deciduous or supernumerary. The maxillary canine and third molar are involved most frequently. ${ }^{5,6}$ Most cases are asymptomatic and are found incidentally on routine clinical and radiological examinations.

Ectopic eruption may result due to one of the three processes: developmental disturbance, pathological process and iatrogenic activity. ${ }^{7}$ Tooth eruption into the maxillary sinus may cause sinusitis, ${ }^{7}$ the treatment of which (if infected) is surgical removal. ${ }^{1}$ We present a case of an ectopic maxillary third molar, which presented in the left maxillary sinus with purulent rhinorrhea and was removed via a Caldwell-Luc procedure.

\section{CASE REPORT}

A 19-year-old female reported with a complaint of recurrent purulent rhinorrhea on the left nasal cavity. The problem did not resolve in spite of taking medication for 6 months. Detailed endoscopic examination showed a congested mucosa of inferior turbinate along with medialization of middle turbinate with bulging of ethmoidal bulla and purulent discharge along with polyp arising from middle meatus filling the nasal cavity posteriorly till choana. Local examination and other investigations were within normal limits and the patient was then planned for surgical management for which computed tomographic (CT) scan of paranasal sinuses with axial and coronal cuts was done on which an expansile cyst with an ectopic molar in the left maxillary sinus was observed arising from the posterolateral wall of the sinus (Fig. 1). There was no previous history of any trauma or surgical intervention or any chronic infection of oral cavity.

The patient subsequently underwent removal of the cyst under general anesthesia via a Caldwell-Luc procedure. A vestibular incision was made from lateral incisor up to the first molar tooth. A bony window was created and the diseased mucosa along with cyst line and the tooth were removed. The polyp was removed by endoscopic sinus surgery. Hemostasis was achieved by placing a pack through antrostomy window created in the inferior meatus along with packing of nasal cavity and the wound closed with 3.0 vicryl sutures. The pack was removed on 3rd postoperative day under antibiotic cover and the patient was discharged. The entire specimen was sent for histopathological examination.

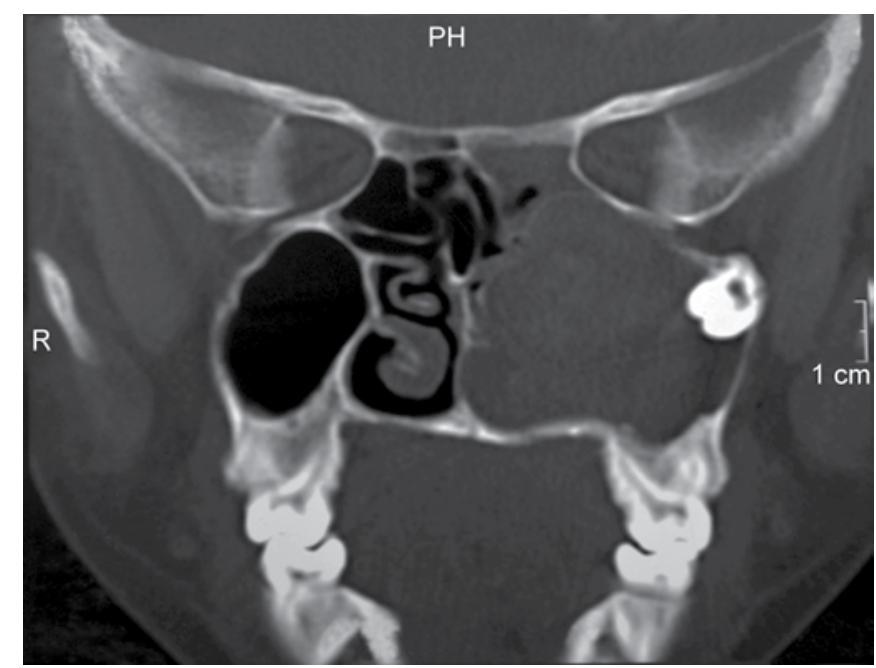

Fig. 1: NCCT PNS showing a bony expansile cyst associated with an ectopic tooth in left maxillary sinus extending up to posterior ethmoids associated with a nasal polyp filling left nasal cavity 
The histology report came back as a maxillary molar tooth encased by a cyst lined by nonkeratinized stratified squamous epithelium with dystrophic calcification and clusters of mucous cells found within the cysts. The histology report of specimen from nasal cavity was suggestive of inflammatory nasal polyp. There was complete resolution of symptoms after 1 month of follow-up.

\section{DISCUSSION}

Tooth development results from an interaction between the oral epithelium and the underlying mesenchymal tissue. This process begins in the 6th week in utero with the formation of maxillary and mandibular dental lamina in the region of the future alveolar process. This ectodermal derivative undergoes proliferation to form the permanent dentition between the 5th and 10th months, with each mature tooth consisting of a crown and a root. ${ }^{8}$ Abnormal tissue interactions during development may potentially result in ectopic tooth development and eruption.

Commonly ectopic eruption of tooth occurs in the oral cavity and essentially in normal position but rare localizations like nasal septum, ${ }^{9}$ mandibular condyle, ${ }^{10}$ coronoid process, ${ }^{11}$ palate and maxillary sinus ${ }^{12}$ has been reported. Occasionally, the tooth may erupt into the maxillary antrum and present with local sinonasal symptoms attributed to recurrent or chronic sinusitis. Dentigerous cyst is the most common of all follicular cysts, more common in males, occurring in the second or third decade of life. About 70\% of dentigerous cysts occur in the mandible and $30 \%$ in the maxilla. ${ }^{13}$ If infected, the treatment of choice is complete enucleation of the lesion intraorally with removal of the associated tooth. It is also important to completely remove all diseased antral tissues and thoroughly assess all resected soft tissue histologically. ${ }^{14}$ The diagnosis of this condition can be made radiographically with plain sinus X-rays and CT scans taken in axial and coronal sections.

The treatment of an ectopic tooth in the maxillary sinus is usually removal because if left untreated, it has the tendency to form a cyst or tumor and/or the lesion may cause perforation of the orbital floor and obliteration of the nasal cavity. Caldwell-Luc procedure and endoscopic sinus surgery were done in this case as the ectopic tooth was the cause of dentigerous cyst leading to recurrent sinusitis and purulent rhinorrhea in spite of administering antibiotics repeatedly.

\section{REFERENCES}

1. Goh YH. Ectopic eruption of maxillary molar tooth--an unusual cause of recurrent sinusitis. Singapore Med J 2001 Feb;42(2): 80-81.

2. Erkmen N, Olmez S, Onerci M. Supernumerary tooth in the maxillary sinus: case report. Aust Dent J 1998 Dec;43(6): 385-386.

3. Gulbranson SH, Wolfrey JD, Raines JM, McNally BP. Squamous cell carcinoma arising in a dentigerous cyst in a 16-month old girl. Otolaryngol Head Neck Surg 2002 Nov;127(5):463-464.

4. Ustuner E, Fitoz S, Atasoy C, Erden I, Akyar S. Bilateral maxillary dentigerous cysts: a case report. Oral Surg Oral Med Oral Pathol Oral Radiol Endod 2003 May;95(5):632-635.

5. Takagi S, Koyama S. Guided eruption of an impacted second premolar associated with a dentigerous cyst in the maxillary sinus of a 6-year-old child. J Oral Maxillofac Surg 1998 Feb;56(2): 237-239.

6. Avitia S, Hamilton JS, Osborne RF. Dentigerous cyst presenting as orbital proptosis. Ear Nose Throat J 2007 Jan;86(1):23-24.

7. Bodner L, Tovi F, Bar-Ziv J. Teeth in the maxillary sinus--imaging and management. J Laryngol Otol 1997 Sep;111(9):820-824.

8. Avery, James K. Oral Development and histology. 2nd ed. New York: Thieme Medical Publisher Inc; 1994. 70-92 p.

9. el-Sayed Y. Sinonasal teeth. J Otolaryngol 1995 Jun;24(3):180-183.

10. Yusuf H, Quayle AA. Intracondylar tooth. Int J Oral Maxillofac Surg 1989 Dec;18(6):323.

11. Toranzo Fernandez M, Terrones Meraz MA. Infected cyst in the coronoid process. Oral Surg Oral Med Oral Pathol. 1992 Jun;73(6):768.

12. Pracy JP, Williams HO, Montgomery PQ. Nasal teeth. J Laryngol Otol 1992 Apr;106(4):366-367.

13. Bhaskar, Surindar Nath. Synopsis of oral pathology. 7th ed. United States: CBS Publisher; 1986. 228-237 p.

14. Laskin DM. Oral surgery. 1st ed. Missouri: Cr. Mosby; 1996. $459 \mathrm{p}$.

\section{ABOUT THE AUTHORS}

\section{Nitin Kumar Jain}

Junior Resident, Department of Otorhinolaryngology, GSVM Medical College, Kanpur, Uttar Pradesh, India

Correspondence Address: Room No. 57, PG Boys Hostel, GSVM Medical College, Kanpur, Uttar Pradesh, India, Phone: 8853207095, e-mail: nitinjain70@gmail.com

\section{Siddharth Vashistha}

Junior Resident, Department of Otorhinolaryngology, GSVM Medical College, Kanpur, Uttar Pradesh, India

\section{Megha Jain}

Postgraduate Student, Department of Oral Pathology and Microbiology People's College of Dental Science and Research Centre, Bhopal Madhya Pradesh, India 